\title{
Laminar Flow of Spherical Body in Horizontal Pipeline
}

\author{
Farhan Lafta Rasheed \& Abdulsattar k. Abbas \\ Ministry of Sciences and Technology, Baghdad-Iraq
}

Received: August 8, 2011

Accepted: August 26, 2011

doi:10.5539/mas.v5n5p221

\begin{abstract}
An analytical model for the flow of spherical body in pipeline with density equal to that of water in laminar flow condition was obtained.A good agreement between the theoretical results obtained from the present work with that obtained from the literature.Results were obtained for the flow of spherical body in 0.03 mdiameter, sphere/pipe diameter ratio, $\mathrm{k}$, corresponding to $0.6,0.7$ and 0.8 . The average flow velocity varied from 0.036 to $0.073 \mathrm{~m} / \mathrm{s}$.Increasing the average flow velocity will increase the pressure gradient. Increasing sphere/pipe diameter ratio will increase the pressure gradient.
\end{abstract}

Keywords: Capsule flow, Capsule pipeline, Hydro transport, Hydraulic transport pipeline, Freight pipeline

\section{Introduction}

The power of a moving fluid of picking up and carrying solids considerably denser than itself has long been identified with the erosion, transport and deposition of soil and rock particles in nature by air and by water. Its application to the conveyance of solids in pipelines offers a means of transportation which by virtue of its simplicity, continuityand, in some instances, economy, may prove to be advantageous over the conventional means of transport (Button, 1974).

Ellis(1964) have obtained general expressions for the incremental pressure drop experienced by a piped viscous fluid due to the motion of a particulate sphere along the axis of the pipe.

No analysis of the pressure gradient for the flow of either concentric or eccentric spherical capsule is known. In the former case, however, wherethere is no energy loss due to solid friction, it is reasonable to assume that the pressure gradient in the presence of a capsule train would be close to that which would occur with the flow of a single-phase liquid of mixture density and at the mixture velocity. Specifically we might expect a pressure gradient in a horizontal line(Govier,1972):

$\left(\frac{\Delta P}{L}\right)_{S}=\frac{2 f \rho_{M S} u_{a v}^{2}}{D}$

$\rho_{M S}$ Where $\mathrm{f}$ is the single-phase friction factor based upon, and $\operatorname{Re}_{l}=\frac{D u_{a v} \rho}{\mu}$ Is the density of the sphere-liquid mixture, which given by: $\rho_{M s}=\rho\left[\frac{2}{3} k^{2}(s-1)+1\right]$

Where s is the density ratio, $s=\frac{\rho_{S}}{\rho}$, and $\rho_{S}=$ sphere density, $\rho=$ fluid density

Harries et al. (2003) developed a numerical model to simulate the segmental liquid-liquid flow. The general purpose CFD code4 was extended in order to predict the internal flow patterns of fluid segments and the transfer of dissolved chemical species within segments and across fluid segment interfaces.Klinzing( 1989) made a force balance to the flow of solid in gas stream to predict the pressure gradient in inclined pipe.

When there is no energy loss due to solid friction, it is reasonable to assume that the pressure gradient in the presence of a sphere train would be close to that which would occur with the flow of a single-sphere liquid of mixture density and at the mixture velocity. 


\section{Theoretical Analysis}

Consider a spherical body flowing in a concentric position relative to the pipe wall under the influence of a fluid stream in laminar flow as shown in fig. (1). Under steady state conditions the fluid will in unidirectional motion and the basic differential equation (written in spherical coordinates) is (Hughes,1967):

$\frac{\partial^{2} u}{\partial r^{2}}+\frac{2 \partial u}{r d r}=\frac{1}{\mu}\left(\frac{\Delta P}{L}\right)_{S}$

Eq. (1) may be rearranged to:

$\frac{1}{r^{2}} \frac{\partial}{\partial r}\left(r^{2} \frac{\partial u}{\partial r}\right)=\frac{1}{\mu}\left(\frac{\Delta P}{L}\right)_{S}$

In addition, integrated twice to give the fluid velocity, andwith the following boundary conditions:

$\mathrm{U}=0$ when $\mathrm{r}=\mathrm{R}_{2} \mathrm{Andu}=\mathrm{u}_{\mathrm{s}}$ when $\mathrm{r}=\mathrm{R}_{1}$

Yield:

$u=\frac{1}{6 \mu}\left(\frac{\Delta P}{L}\right)_{S}\left(R_{2}^{2}-r^{2}\right)$

Further $\mathrm{u}=\mathrm{u}_{\mathrm{s}}$ for $0<\mathrm{r}<\mathrm{R}_{1}$

Thus, the sphere velocity is given by:

$u_{S}=\frac{1}{6 \mu}\left(\frac{\Delta P}{L}\right)_{S}\left(R_{2}^{2}-R_{1}^{2}\right)$

Eq.s (3), (4) and (5) completely define the velocity profile. Now the volumetric flow rate of fluid in the annulus between the sphere and the pipe wall is given by:

$Q_{a n n}=2 \pi \int_{R_{2}-r_{1} \sin }^{R_{2}} \int_{\theta=0}^{\pi} r u d r d \theta$

Integration eq. (6) after substituting the value of $\mathrm{u}$ from eq. (3) gives:

$$
\begin{aligned}
Q_{a n n} & =\frac{-\pi}{3 \mu}\left(\frac{\Delta P}{L}\right)_{S}\left(\frac{\pi R_{2}^{2} R_{1}^{2}}{2}-2 R_{2} R_{1}^{3}+\frac{3 \pi R_{1}^{4}}{32}\right) \\
& =\frac{2 \pi u_{S}}{\left(R_{2}^{2}-R_{1}^{2}\right)}\left(\frac{\pi R_{2}^{2} R_{1}^{2}}{2}-2 R_{2} R_{1}^{3}+\frac{3 \pi R_{1}^{4}}{32}\right)
\end{aligned}
$$

The volumetric throughput of sphere is simply:

$$
Q_{S}=\frac{2}{3} \pi R_{1}^{2} u_{s}
$$

The average flow velocity is obtained by dividing the total volumetric flow rate by the cross-section area.

Thus:

$$
u_{a v}=\frac{Q_{a n n}+Q_{S}}{\pi R_{2}^{2}}
$$

In addition, usingeq.s (7) \& (8) we obtain: 


$$
u_{S}=\frac{\left(1-k^{2}\right) u_{a v}}{\pi k^{2}-4 k^{3}+\frac{3}{16} \pi k^{4}+\frac{2}{3} k^{2}\left(1-k^{2}\right)}
$$

Eq. (10) represents the relationship between the sphere velocity and the average flow velocity under laminar flow conditions.

Eq. (5) may be rearranged to find the pressure gradient caused by sphere:

$$
\left(\frac{\Delta P}{L}\right)_{S}=\frac{6 \mu u_{S}}{\left(R_{2}^{2}-R_{1}^{2}\right)}
$$

Introducing eq. (10) in eq. (11) yield:

$$
\left(\frac{\Delta P}{L}\right)_{S}=\frac{6 \mu}{\left(R_{2}^{2}-R_{1}^{2}\right)}\left[\frac{\left(1-k^{2}\right) u_{a v}}{\pi k^{2}-4 k^{3}+\frac{3}{16} \pi k^{4}+\frac{2}{3} k^{2}\left(1-k^{2}\right)}\right]
$$

\section{Results and Discussion:}

Results were obtained for the flow of spherical body in water pipeline with density equal to that of water in 0.03 $\mathrm{m}$ pipe diameter, sphere/pipe diameter ratio equal to $0.6,0.7$ and 0.8 . The average flow velocity of water ranged from 0.036 to $0.073 \mathrm{~m} / \mathrm{s}$ corresponding to $\mathrm{Re}=1000$ to 2000 (laminar flow).

Fig.(2) represents the relationship between the pressure gradient caused by spherical body and average flow velocity for horizontal pipeline, in which the increase in average flow velocity caused an increase in the pressure gradient.

Fig. $s(3,4)$ are the same as fig. (2) except $\mathrm{k}=0.7$ and 0.8 respectively. From fig. $\mathrm{s}(2,3$ and 4$)$, one can observe that the increase in $\mathrm{k}$ value will increase the pressure gradient caused by sphere.

\section{Conclusions:}

The following conclusions were obtainedfrom the present work:

1. Increasing the average flow velocity will increase the pressure gradient.

2. Increasing the $\mathrm{k}$ value will increase the pressure gradient.

3. A good agreement between the theoretical results obtained from the present work with that obtained from literature (Govier, 1972).

\section{References}

Button,B.1.,M.A.,T.H. (1974). "Hydraulic Transport of Single Capsule in a Horizontal pipe",ASME,p.1(1974),New York.

Ellis, H.S. (1964). "The Pipeline Flow of capsules", Can.J.Chem.Eng.42 (1964a), p1. doi:10.1002/cjce.5450420101, http://dx.doi.org/10.1002/cjce.5450420101

Govier, G.W. and Aziz, K. (1972). "The Flow of Complex Mixtures in Pipelines", VanNostrand Reinhold, New York, 1972.

Hughes, W.F. and Brighton, j.A. (1967). "Fluid Dynamics", McGraw-Hill Book Company, 1967.

Harries, N., Burns, J. R., Barrow, D. A., \&Ramshaw, C. (2003). A numerical model for segmented flow in a microreactor, International J. of Heat and Mass Transfer, 46, 3313-3322. doi:10.1016/S0017-9310(03)00120-0, http://dx.doi.org/10.1016/S0017-9310(03)00120-0

Klinzing et al. (1989). "Pneumatic Transport of Solids in Inclined Geometry", Can.J.Chem.Eng.67 (1989), p237. doi:10.1002/cjce.5450670210, http://dx.doi.org/10.1002/cjce.5450670210

Polderman, H.G. (1982). "Design Rules for Hydraulic Capsule Transport System", J.Pipeline, 3(1982), p.123 


\section{Nomenclature:}

\section{ParameterDefinition}

$\mathrm{K}$

Sphere/pipe diameter or radius ratio $\left(R_{1} / R_{2}\right)$

$\left(\frac{\Delta P}{L}\right)_{S}$

Pressure gradient caused by sphere $\left(\mathrm{N} / \mathrm{m}^{3}\right)$

Qann $\quad$ Volumetric flow rate in the annulus $\left(\mathrm{m}^{3} / \mathrm{s}\right)$

Qs $\quad$ Sphere volumetric flow rate $\left(\mathrm{m}^{3} / \mathrm{s}\right)$

$\mathrm{R}_{1} \quad$ Outside sphere $\operatorname{radius}(\mathrm{m})$

$\mathrm{R}_{2} \quad$ Inside pipe $\operatorname{radius}(\mathrm{m})$

Pipe Reynolds number $\left(\rho u_{\mathrm{av}} \mathrm{D} / \mu\right) \quad \mathrm{Re}$

Average flow velocity $(\mathrm{m} / \mathrm{s})$

Sphere velocity $(\mathrm{m} / \mathrm{s})$

\section{Greek Symbols}

$\rho$

$\rho_{\mathrm{s}}$

$\mu$

$\theta$

\author{
Fluid density $\left(\mathrm{kg} / \mathrm{m}^{3}\right)$ \\ Sphere density $\left(\mathrm{kg} / \mathrm{m}^{3}\right)$ \\ Dynamic viscosity of the fluid(pa.s) \\ Spherical coordinates(degrees)
}

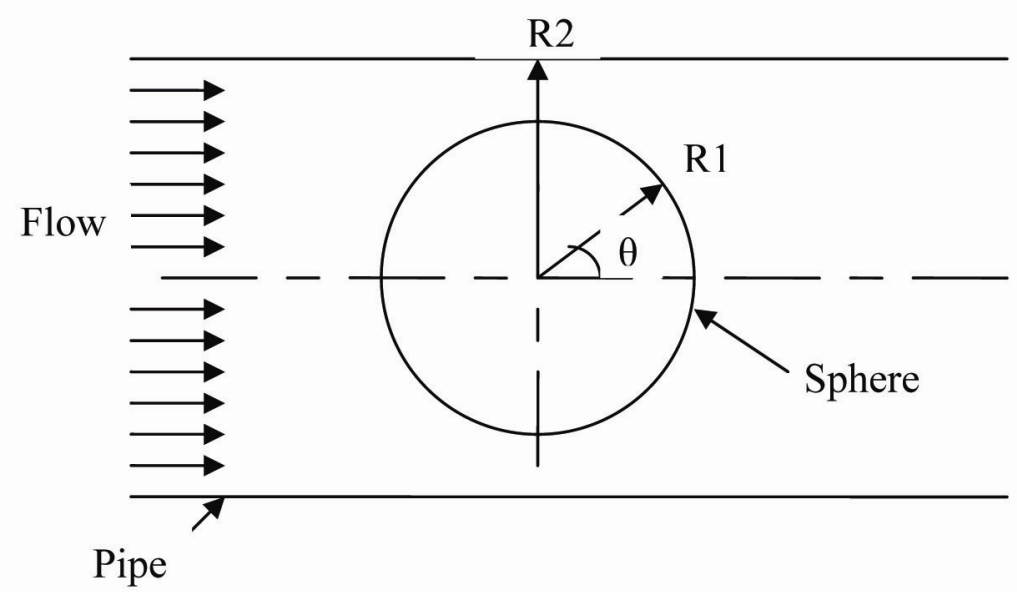

Figure 1. Flow of spherical body in pipeline 


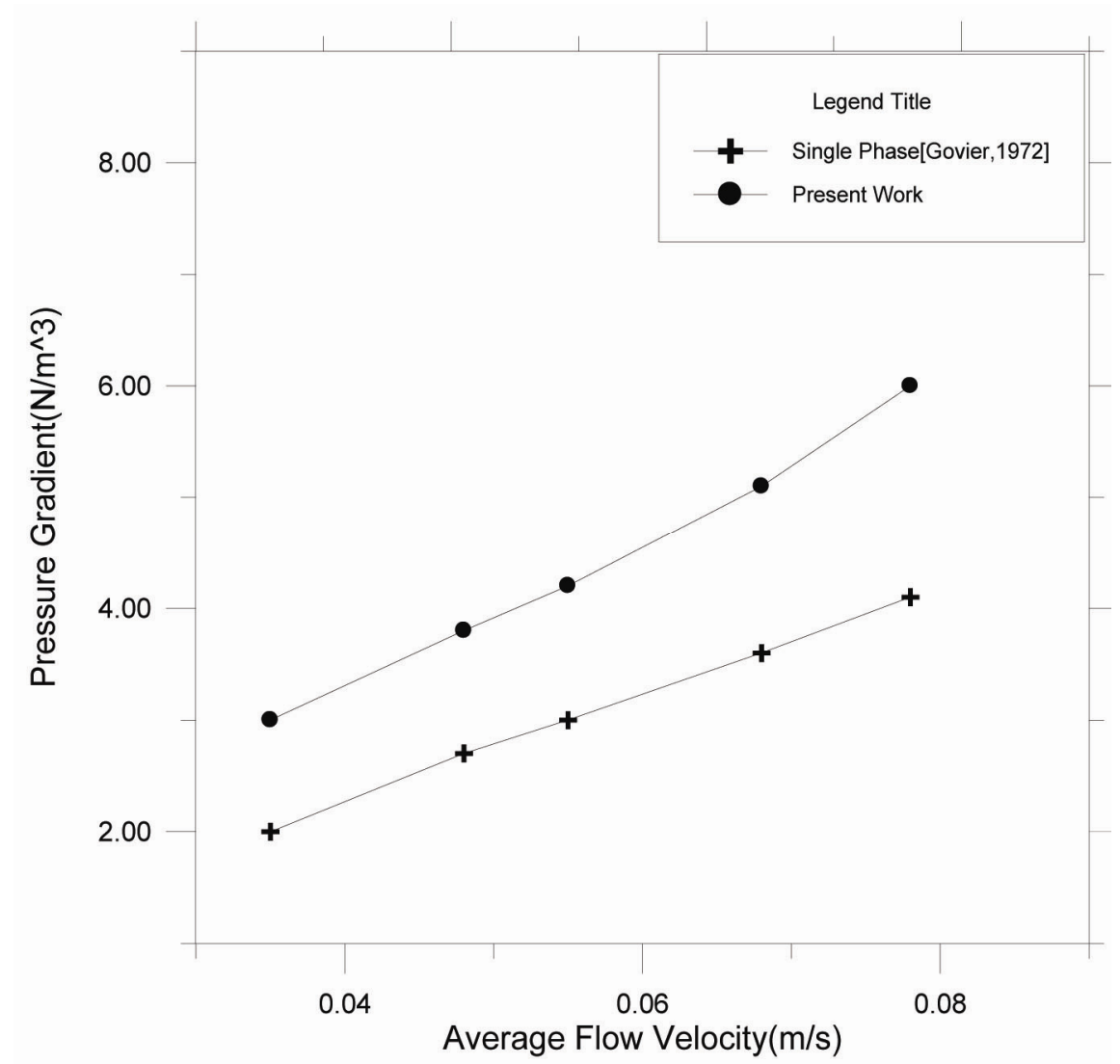

Figure 2. Variation of pressure gradient with average flow velocity for $\mathrm{k}=0.6$

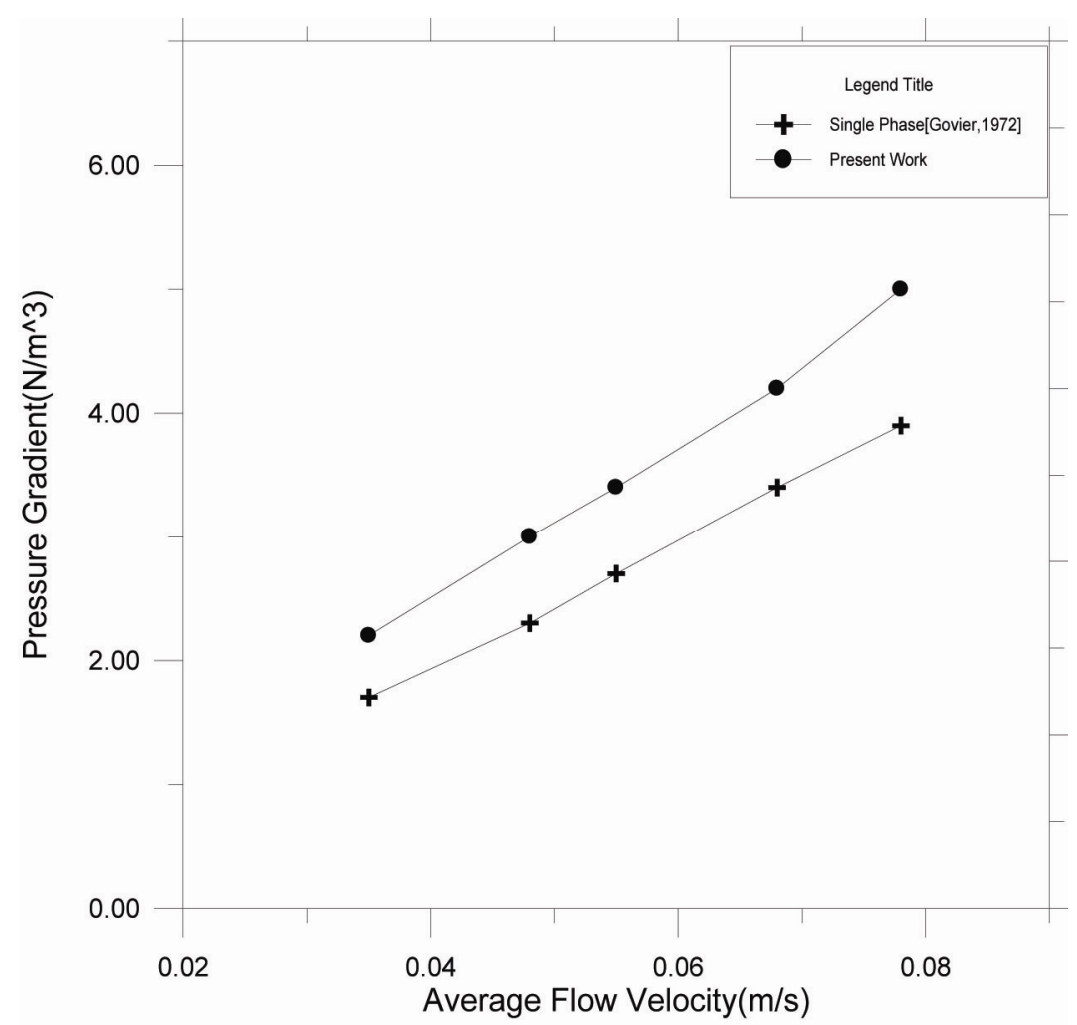

Figure 3. Variation of pressure gradient with average flow velocity for $\mathrm{k}=0.7$ 


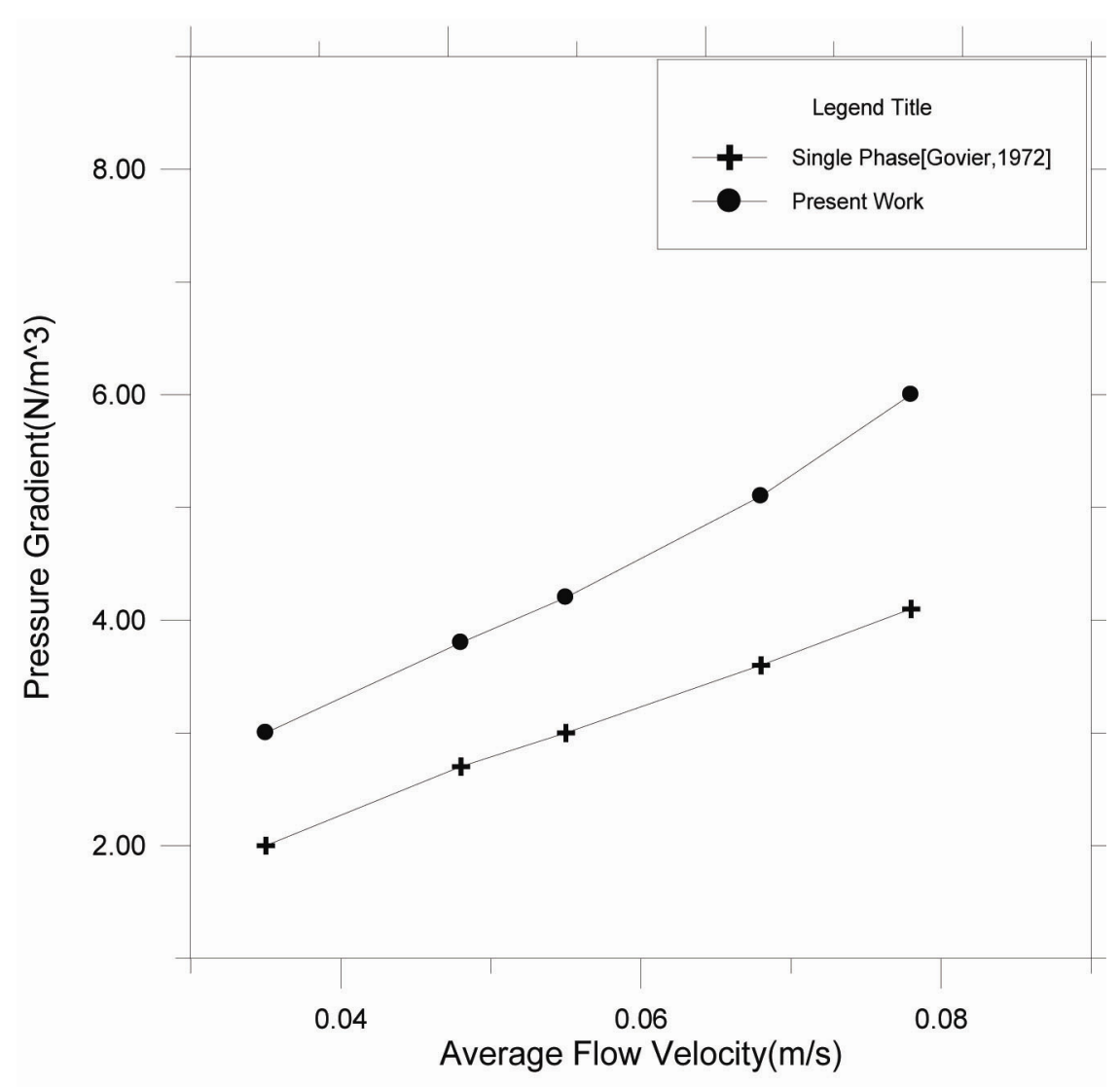

Figure 4. Variation of pressure gradient with average flow velocity for $\mathrm{k}=0.8$ 